\title{
Expression of CA-125 by progestational bovine endometrium: prospective regulation and function
}

\author{
A. C. McDonnel, E. A. Van Kirk, K. J. Austin, T. R. Hansen, E. L. Belden \\ and W. J. Murdoch* \\ Department of Animal Science and Reproductive Biology Program, University of Wyoming, \\ Laramie, WY 82071, USA
}

\begin{abstract}
Cancer antigen 125 (CA-125) is expressed by malignant human ovarian surface epithelial cells and derivatives of the Müllerian duct system. This study explored the expression, regulation, and function of CA-125 in the bovine uterus. CA-125 was localized by immunohistochemistry to the apical surfaces of epithelial cells lining the endometrium and proximal glands of the late luteal phase and early pregnancy; antigen was not detected during oestrus or the postpartum period. Production of CA-125 by bovine endometrial cells in vitro was upregulated by progesterone and
\end{abstract}

interferon- $\tau$. Immunopurified CA-125 from uterine flushes of dioestrous or pregnant cows was similar in biochemical composition (as determined by gel electrophoresis and amino acid content) to the human antigen isolated from incubation medium conditioned by the ovarian cancer cell line OVCAR-3. Bovine CA-125 inhibited complementinduced lysis of antibody-sensitized sheep erythrocytes. It is suggested that endometrial CA-125 exerts a progestational role in part by protecting maternal and embryonic cells from immune targeting and lysis.

\section{Introduction}

Cancer antigen 125 (CA-125) was first identified as an immunogenic determinant on an ovarian adenocarcinoma cell line (Bast et al., 1981). The molecular characterization of CA-125 has since proved to be difficult. Most studies have indicated that CA-125 is a heterogeneous mucinous protein of high molecular mass. Size estimates of CA-125 have ranged from 200 to $2000 \mathrm{kDa}$, and smaller subunits have been reported (O'Brien et al., 1998; Yin and Lloyd, 2001). The gene encoding CA-125 apparently yields a transmembrane molecule with a dominate extracellular motif composed of tandem repeat units, a plasmalemma-spanning domain and short cytoplasmic tail (O'Brien et al., 2001). Serum measurements of secreted forms of CA-125 have proven useful in monitoring the progress of patients with ovarian cancer after cytoreductive surgery and chemotherapy (Meyer and Rustin, 2000).

Most ovarian cancers are thought to arise by clonal transformation of a surface epithelial cell containing DNA damaged by reactive oxidants generated during the process of ovulatory follicular rupture (Murdoch and McDonnel, 2002). Normal ovarian surface epithelial cells are of an uncommitted stem-like phenotype, and cell-surface expression of CA-125 occurs with metaplastic differentiation into a Müllerian-type epithelium

*Correspondence

Email: wmurdoch@uwyo.edu
(Feeley and Wells, 2001). Indeed, CA-125 is not unique to ovarian cancer cells. Epithelia of the female genital tract also express CA-125 (Zeimet et al., 1998). Circulatory CA-125 is higher in patients with endometriosis (Bast et al., 1998).

Normal fluctuations in serum CA-125 (that is, those not associated with ovarian cancer or benign gynaecological disease) appear to be related to stage of the ovarian cycle and pregnancy status. Serum concentrations of CA-125 increase during the folliculo-lutealmenstrual transition of spontaneous human cycles (Bon et al., 1999). Further increases in CA-125 occur in early pregnancy (Bast et al., 1998). In fact, heightened serum CA-125 concentrations are indicative of successful implantation in women after in vitro fertilization and embryo transfer (Baalbergen et al., 2000). Pregnancies equated with multiple corpora lutea after superovulation correlate with higher serum CA-125 than found in normal monovulatory pregnancies (Paoletti et al., 1995). Production of CA-125 by malignant ovarian epithelial cells is upregulated by interferons (Marth et al., 1998). A unique trophoblast-derived interferon (IFN), designated as IFN- $\tau$, is involved in the local endometrial signalling process of pregnancy recognition in ruminants (Demmers et al., 2001).

A patho-physiological function for CA-125 has not been established. In a recent study (A. C. McDonnel and W. J. Murdoch, unpublished), CA-125 of human ovarian cancer cell origin was found to exhibit (as a possible means to resist natural and therapeutic-based immune 
destruction) complement-inhibiting properties. Downregulation of complement activation at the maternalplacental interface protects cells from immune targeting and lytic death (Morgan and Holmes, 2000).

Studies on CA-125 have been almost exclusively on specimens of human origin. The initial objective of this investigation was to determine the spatial distribution and temporal alterations of CA-125 in uterine samples of cyclic, pregnant and postpartum cows. Follow-up studies were designed to evaluate putative endocrine-paracrine (steroid hormonal and IFN) effectors of (endometrial) CA-125 production and to assess the biochemical and functional attributes of bovine CA-125.

\section{Materials and Methods}

Experiments were performed with the approval of the University of Wyoming Animal Care and Use Committee. Reagents were purchased from Sigma Chemical Co. (St Louis, MO) unless indicated otherwise.

\section{Immunohistochemical localization of CA-125}

Angus cross-bred cows were synchronized to oestrus (day 0) with prostaglandin $\mathrm{F}_{2 \alpha}(25 \mathrm{mg}$ dinoprost tromethamine i.m.; Pharmacia and Upjohn, Kalamazoo, MI). Animals allotted to pregnancy groups were inseminated artificially $12 \mathrm{~h}$ after detection of oestrus. Reproductive organs were obtained at slaughter on day 0 (oestrus; $n=3)$, day 18 of the oestrous cycle $(n=4)$, and days $18(n=4), 22(n=4)$ and $50(n=4)$ of pregnancy, and on day 45 after parturition (anoestrus; $n=3$ ). Uterine horns of inseminated females were inspected to confirm the presence of a conceptus or fetus.

Cross-sectional segments of uterine horns were fixed by immersion in Histochoice (Amresco, Solon, OH), washed in PBS, dehydrated in a graded series of ethanol, cleared in xylene, and infiltrated with and embedded in paraffin wax. Sections of $7 \mu \mathrm{m}$ thickness were transferred on to microscope slides treated with subbing solution $(0.025 \%(\mathrm{w} / \mathrm{v})$ chromium potassium sulphate, $0.25 \%$ $(\mathrm{w} / \mathrm{v})$ gelatin), deparaffinized, rehydrated, microwaved in Retrieve-All-1 unmasking solution (Signet Pathology Systems, Dedham, MA), incubated in 10\% normal blocking serum $\left(5 \mathrm{~min}, 24^{\circ} \mathrm{C}\right)$, reacted with mouse monoclonal anti-CA-125 (4 nmol OC- $125 \mathrm{I}^{-1}$ for $1 \mathrm{~h}$; Signet Pathology Systems), washed in PBS, stained using a streptavidin-alkaline phosphate-fast red detection system (Signet Pathology Systems), counterstained in Mayer's haematoxylin, rinsed in distilled water, and coverslips were added (Gel-Mount; Biomeda Corporation, Foster City, CA). Negative controls were performed without primary antibody and with primary antibody preadsorbed with human ovarian cancer cell-derived CA-125 (Research Diagnostics Inc., Flanders, NJ).
Selections of fields of microscopic inspection (three areas per animal; $\times 320$ ) were made at random and without knowledge of stage of cycle or pregnancy. Immunostaining along apical and basal aspects of endometrial luminal epithelium, proximal (within $0.6 \mathrm{~mm}$ of the lumen) glandular epithelium, and distal glandular epithelium were categorized on a scale of 0 to 4 $(0=$ non-detectable, $1=$ scant, $2=$ light, $3=$ moderate, $4=$ heavy).

In vitro effects of steroid hormones and interferon- $\tau$ on cellular CA-125 expression

Endometrial cells established from an epitheliumenriched bovine line (Staggs et al., 1998) were transferred $\left(1 \times 10^{6}\right)$ on to poly-L-lysine coated coverslips (Becton Dickinson, Franklin Lakes, NJ) and incubated (24 h, $37^{\circ} \mathrm{C}, 5 \% \mathrm{CO}_{2}$ ) in Ham's-minimum essential medium (MEM; $1 \mathrm{ml}$ ) supplemented with $0.4 \mathrm{mmol} \mathrm{D}$-valine $\mathrm{I}^{-1}$ and $10 \%$ fetal calf serum (control), plus $3 \mathrm{nmol}$ oestradiol $\mathrm{I}^{-1}, 1 \mu \mathrm{mol}$ progesterone $\mathrm{I}^{-1}$, or $2.5 \mathrm{nmol}$ recombinant bovine $\mid \mathrm{FN}-\tau \mathrm{I}^{-1}$. Each treatment was replicated six times. Doses of steroid hormones and IFN- $\tau$ approximated to local concentrations typical of the oestrous cycle and early pregnancy (Henricks and Harris, 1978; Weems et al., 1988; Benoit and Dailey, 1991; Roberts et al., 1992). Cells immunostained for CA-125 were counted within five randomly selected areas $(\times 160)$ on each coverslip. (In a preliminary study, the cell line was observed to contain a mixture of epithelial and stromal cells and only cytokeratin-positive (that is, epithelial) cells were co-reactive for CA-125.)

Immunopurification and amino acid analysis of CA-125

CA-125 was isolated from a pooled uterine flush of day 18 open (non-pregnant) and pregnant cows $(n=8)$ and incubation medium conditioned by an ovarian carcinoma cell line (OVCAR-3; American Type Culture Collection, Rockville, MD) with the aid of a Seize-X Primary Immunoprecipitation Kit, according to the instructions of the manufacturer (Pierce, Rockford, IL). OC-125 antibody $(100 \mu \mathrm{g})$ was coupled to aminolink gel for antigen retrievals. Eluted products were quantitated by spectrophotometric protein assay (BioRad Laboratories, Hercules, CA), analysed by SDS-PAGE $(8 \%(\mathrm{w} / \mathrm{v})$ acrylamide; samples boiled for $5 \mathrm{~min}$ in Laemmli buffer without $\beta$-mercaptoethanol) with silver staining, and subjected to amino acid composition analysis by ion-exchange chromatography (Molecular Structure Facility, University of California, Davis, CA).

\section{Effect of bovine CA-125 on complement-mediated haemolysis}

A standard cytolytic (haemoglobin-release) activity assay incorporating sheep red blood cells, rabbit antisheep 
erythrocyte antibody, and a complement source (guineapig serum) was used (Mayer, 1984). Briefly, erythrocytes $(4 \mathrm{ml}$ blood) were washed five times in gelatin veronal buffer $\left(0.15 \mathrm{mmol} \mathrm{CaCl}_{2} \mathrm{I}^{-1}, 141 \mathrm{mmol} \mathrm{NaCl} \mathrm{I}{ }^{-1}, 0.1 \%\right.$ $(\mathrm{w} / \mathrm{v})$ gelatin, $1.8 \mathrm{~m} \mathrm{~mol}$ sodium barbital $\mathrm{I}^{-1}, 3.1 \mathrm{mmol}$ barbituric acid $\mathrm{I}^{-1} ; \mathrm{pH} 7.3$ ) and sensitized with $1 \mathrm{U}$ antisheep haemolysin (Colorado Serum Co., Denver,

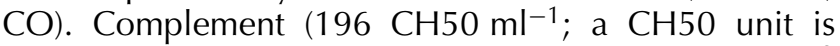
defined as the volume that causes $50 \%$ lysis of $5 \times 10^{8}$ antibody-sensitized erythrocytes at $37^{\circ} \mathrm{C}$ for $1 \mathrm{~h}$ in a $7.5 \mathrm{ml}$ reaction mixture) was titrated to achieve $50 \%$ lysis during a $40 \mathrm{~min}$ incubation at $37^{\circ} \mathrm{C}$. Samples were diluted sixfold with $0.15 \mathrm{~mol} \mathrm{NaCl} \mathrm{I-1}$; cells were pelleted by centrifugation for $5 \mathrm{~min}$ at $450 \mathrm{~g}$, and supernatants were analysed by spectrophotometry $(412 \mathrm{~nm})$. Triplicate reactions were performed in the presence of immunopurified CA-125 $(0,10,20$ or $30 \mu \mathrm{g}$.

\section{Statistical analysis}

Group and treatment mean comparisons were made by analysis of variance and Fisher's protected least significant difference test. Contrasts were considered significantly different at $P<0.05$.

\section{Results}

An immunoreactive CA-125-like antigen was localized by histochemistry at the apical surfaces of progestational bovine endometrial epithelia associated with the uterine lumen and proximal glands. Endometrial glands distanced from the uterine lumen and basal regions of cells (regardless of the site of analysis) did not immunostain. Apical staining reactions ranged from nondetectable on day 0 (oestrus) and day 45 after parturition (anoestrus), increased on day 18, and were most intense during pregnancy $(P<0.05)$. Intensities of staining were similar in cyclic and pregnant cows on day 18 and on days 22 and 50 of pregnancy. There were no significant differences in apical staining intensities between cells bordering the uterine lumen and those cells associated with proximal glands (Figs 1 and 2).

Expression of CA- 125 by bovine endometrial cells was induced by progesterone or IFN- $\tau(P<0.01)$. There were no apparent differences due to in vitro treatments in intensity of immunostaining (that is, responses were positive or negative). The response to IFN- $\tau$ tended to be greater than that to progesterone; however, the contrast between these treatment groups was not statistically significant. Exposure of endometrial cells to oestradiol had no effect on CA-125 expression (Fig. 3).

Purified CA-125 from OVCAR-3 incubation medium and bovine uterine flush migrated in parallel during electrophoresis, revealing a dominant high molecular mass
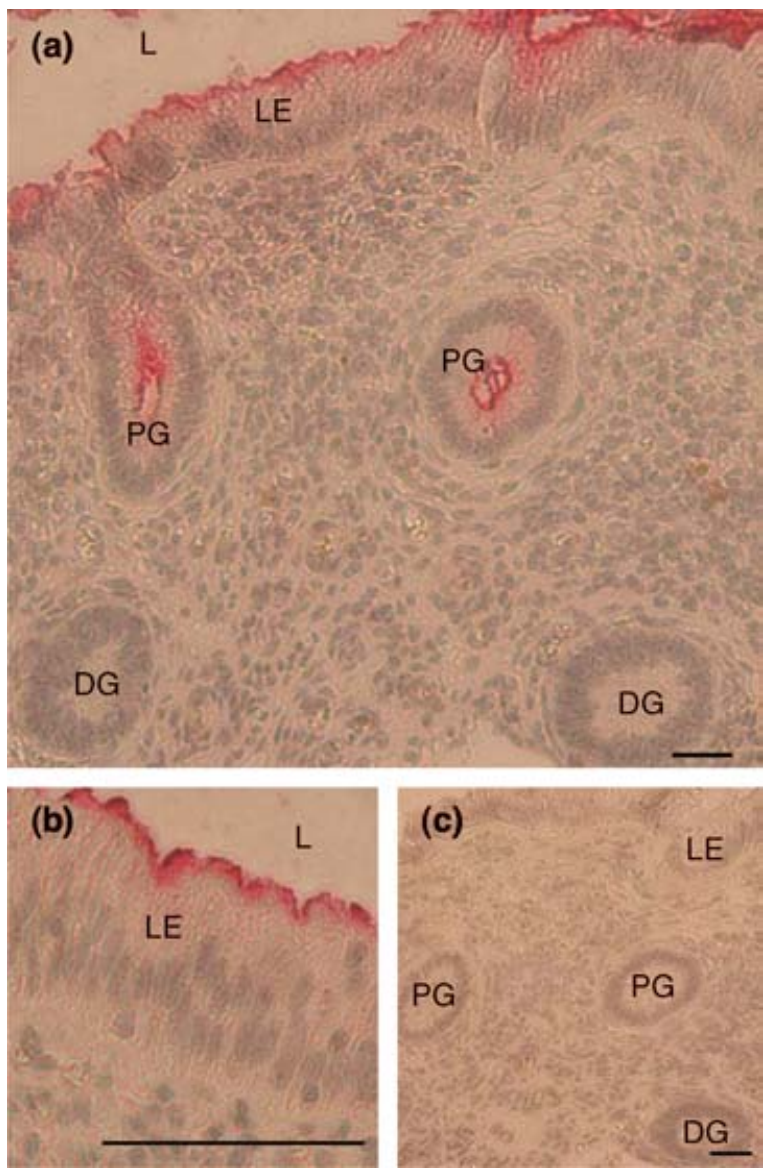

Fig. 1. Representative light photomicrographs of bovine endometrial cancer antigen 125 (CA-125) immunoreactions (day 22 of pregnancy). (a) Cross-sectional view of luminal epithelium and glands. (b) Luminal epithelium illustrating apical localization. (c) Negative control section. DG: distal gland; L: lumen; LE: luminal epithelium; PG: proximal gland. Scale bars represent $0.1 \mathrm{~mm}$.

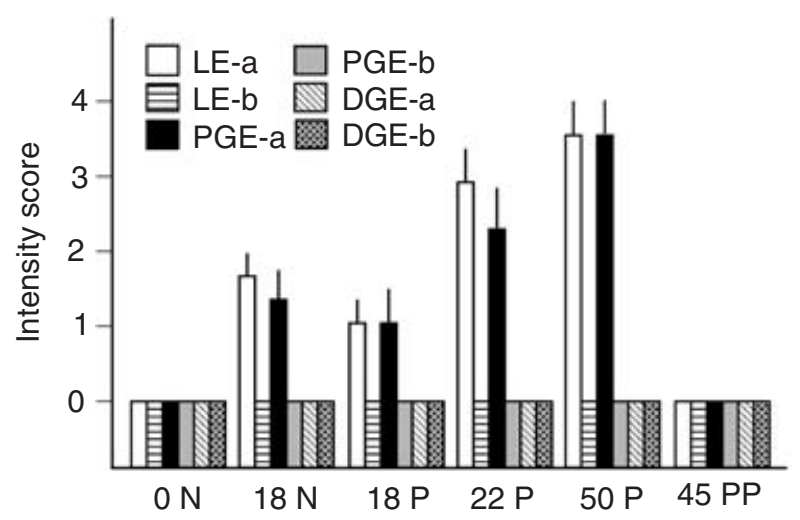

Fig. 2. Quantification of cancer antigen 125 (CA-125) immunostaining (intensity scores) in bovine endometrium. Means + SE are plotted. Days $=0,18,22,45,50$. N: non-pregnant; P: pregnant; PP, postpartum; LE: luminal epithelium; PGE: proximal gland epithelium; DGE: distal gland epithelium; a: apex; b: base. 


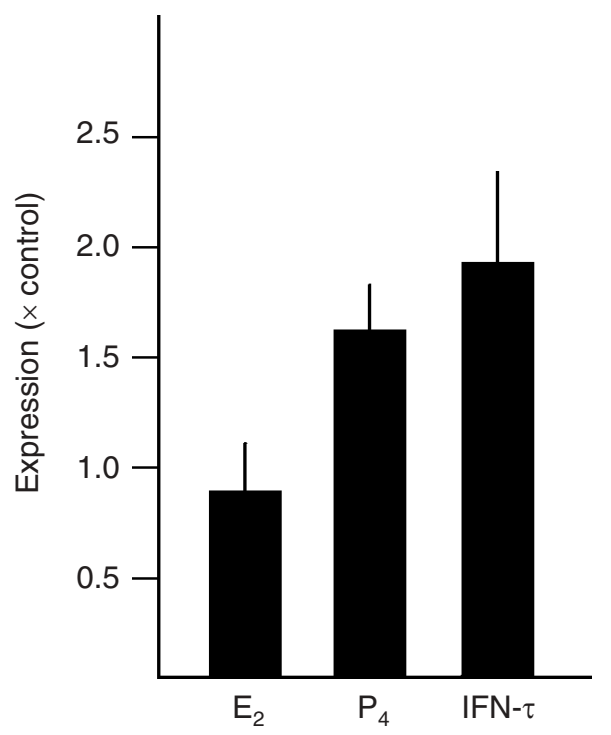

Fig. 3. Effects of steroid hormones and interferon $\tau$ (IFN- $\tau)$ in vitro on cancer antigen 125 (CA-125) expression by bovine endometrial cells. $\mathrm{E}_{2}$ : oestradiol; $\mathrm{P}_{4}$ : progesterone.

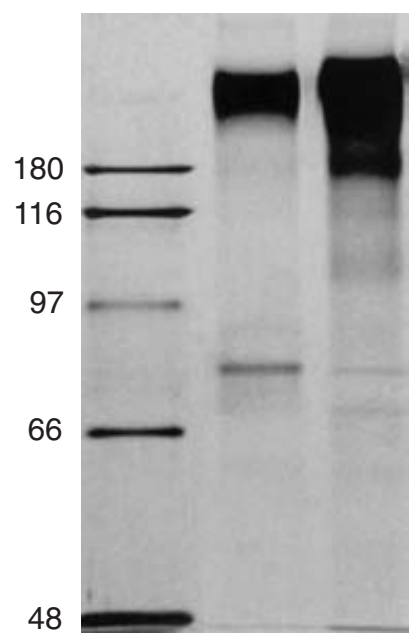

Fig. 4. Gel electrophoresis of immunopurified cancer antigen 125 (CA-125) (0.1 $\mu$ g loaded per lane) from conditioned medium of human epithelial cancer cells (centre) and bovine uterine flush (right). Molecular mass markers ( $\mathrm{kDa}$ ) are shown in the left lane.

fraction of approximately $200 \mathrm{kDa}$; proteins from the uterine flush appeared somewhat more heterogeneous than the human antigen. An additional protein band of about $80 \mathrm{kDa}$ was apparent in the human sample (Fig. 4). Amino acid compositions of the human and bovine samples were similar (Table 1 ).

Uterine CA-125 invoked a linear dose-dependent inhibition $(P<0.01)$ of complement-induced lysis of antibody-sensitized sheep erythrocytes (Fig. 5).
Table 1. Amino acid contents (molecular weight fraction contributed; mol \%) of immunopurified cancer antigen 125 (CA-125) derived from human epithelial ovarian cancer cells and bovine dioestrous-pregnant uterine fluid

\begin{tabular}{lcc}
\hline & \multicolumn{2}{c}{ Immunopurified CA-125 content (mol \%) } \\
\cline { 2 - 3 } Amino acid & $\begin{array}{c}\text { Human epithelial } \\
\text { ovarian cancer cells }\end{array}$ & $\begin{array}{c}\text { Bovine dioestrous- } \\
\text { pregnant uterine fluid }\end{array}$ \\
\hline Asx & 8.7 & 8.4 \\
Glx & 10.3 & 10.1 \\
Ser & 13.4 & 14.3 \\
Gly & 9.6 & 10.5 \\
His & 5.7 & 2.0 \\
Arg & 3.2 & 3.2 \\
Thr & 7.6 & 9.2 \\
Ala & 10.7 & 7.0 \\
Pro & 5.0 & 6.1 \\
Tyr & 3.4 & 3.6 \\
Val & 7.7 & 9.1 \\
Iso & 1.8 & 2.4 \\
Leu & 5.5 & 6.4 \\
Phe & 2.4 & 2.8 \\
Lys & 4.9 & 5.0 \\
\hline
\end{tabular}

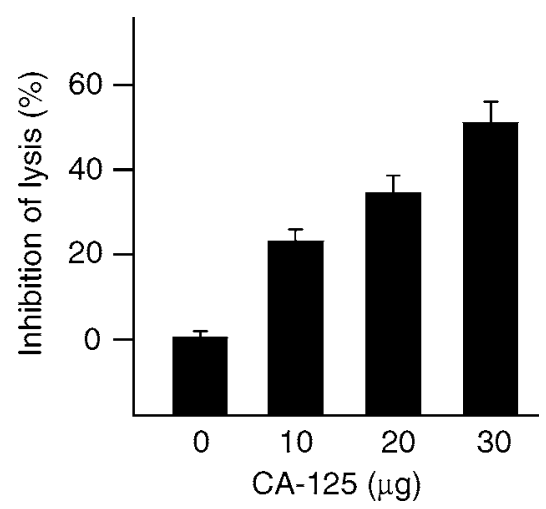

Fig. 5. Effect of bovine cancer antigen 125 (CA-125) on complement-mediated haemolysis of sensitized sheep red blood cells.

\section{Discussion}

Results of these experiments indicate that a humanlike CA-125 antigen is expressed at the apical surfaces of epithelia contiguous with the uterine cavity and proximal glands of cows. Concentations of CA-125 increased during the shift from the late luteal phase of the oestrous cycle through the period of luteal rescue and into pregnancy, intimating a progestational role. Progesterone and IFN- $\tau$ appear to act as inducers of CA-125 production.

This is the first report to the present authors' knowledge demonstrating the presence of CA-125 within the genital tract of a farm species. As well as in humans, positive immunostaining for CA-125 has been identified in Müllerian-derived epithelia of rabbits, dogs and 
monkeys (Nouwen et al., 1990). Circulatory fluctuations in CA-125, which reflect endometrial dynamics during menstrual cycles and human pregnancy, were not predictive of reproductive status in cows; concentrations of CA-125 in jugular serum of cyclic and pregnant animals (as measured by commercial radio- and enzyme-linked immunoassays) were undetectable or highly variable (A. C. McDonnel and W. J. Murdoch, unpublished).

Molecular avenues of regulation of CA-125 biosynthesis and secretion are evidently multifaceted. The classical mode of progesterone action involves hormonal binding to an intracellular (nuclear) receptor, initiating gene transcription (Beato and Sánchez-Pacheco, 1996). However, cyclic expression of progesterone receptors by bovine uterine epithelial cells in vivo was relatively low during the late luteal phase (Robinson et al., 2001); thus, the physiological significance of the present results in vitro (indicating upregulation of CA-125 by progesterone) remain equivocal. Type-I interferons activate a plasma membrane receptor coupled to the Jak-Stat transduction pathway (Prejean and Colamonici, 2000). Proteolytic release of CA-125 from the membrane surface (for example, during cellular death or in response to epidermal growth factor) is dependent upon a phosphorylation event within its cytoplasmic domain (Fendrick et al., 1997; Beck et al., 1998; O'Brien et al., 2001).

The biochemical character of bovine uterine CA-125 seems closely related to the human cancer antigen. Electrophoretic migration patterns and amino acid compositions of CA-125 observed in this study are in agreement with previous descriptions of the human antigen (O'Brien et al., 2001; Yin and Lloyd, 2001).

The findings of the differential expression of CA-125 along mucosal surfaces particularly susceptible to mechanical or chemical injury implies an intrinsic protective function perhaps related to its mucinous nature. Complement inactivation-entrapment is a possibility. A battery of diverse proteins (for example, decay-accelerating factor, membrane cofactor protein, protectin, complement receptor 1 ), which operate in the fluid phase and on plasma membranes prevent inappropriate complement fixation and autolysis; this is certainly the case at the endometrial-placental interface (Morgan and Holmes, 2000). Preliminary findings of the present investigation indicate that CA-125 is a prospective regulator of the complement system in cattle. CA-125 could also potentially alter the adhesive properties of glandular epithelia (maintaining patency) and of the endometrium toward the developing conceptus. Highly glycosylated mucins with large exodomains (for example, Muc-1) are generally thought to mask adhesion molecules (DeSouza et al., 1999). Endometrial expression of Muc-1 by luminal epithelia of mice, pigs, and sheep decreased near the time of blastocyst apposition (Surveyor et al., 1995; Bowen et al., 1996; Johnson et al., 2001); overall Muc-1 concentrations increased in rabbits and humans, but were attenuated at localized sites of trophectoderm attachment (Hoffman et al., 1998; Aplin, 1999). Moreover, Muc-1 is a potent glandular morphogen (Hudson et al., 2001). Formation during the luteal phase of endometrial glands, which become the source of nutrients (histotrophe) for the preimplantation embryo, is essential for the establishment of pregnancy; this is especially important in species (including cows) that do not implant intrusively (Gray et al., 2001). Future studies should be directed at ascertaining the biological significance of CA-125 in uterine functions.

The authors thank R. M. Roberts (University of Missouri, Columbia, MO) for providing the IFN $-\tau$.

\section{References}

Aplin JD (1999) Muc-1 glycosylation in endometrium: possible roles of the apical glycocalyx at implantation Human Reproduction 14 Supplement 2 17-25

Baalbergen A, Janssen JW and van der Weiden RM (2000) CA-125 levels are related to the likelihood of pregnancy after in vitro fertilization and embryo transfer American Journal of Reproductive Immunology $4321-24$

Bast RC, Jr, Feeney M, Lazarus H, Nadler LM, Colvin RB and Knapp RC (1981) Reactivity of a monoclonal antibody with human ovarian carcinoma Journal of Clinical Investigation 68 1331-1337

Bast RC, Xu F-J, Yu Y-H, Barnhill S, Zhang Z and Mills GB (1998) CA 125: the past and future International Journal of Biological Markers 13 179-187

Beato M and Sánchez-Pacheco A (1996) Interaction of steroid hormone receptors with the transcription initiation complex Endocrine Reviews 17 587-609

Beck EP, Moldenhauer A, Merkle E, Kiesewetter F, Jäger W, Wildt L and Lang $\mathbf{N}$ (1998) CA 125 production and release by ovarian cancer cells in vitro. International Journal of Biological Markers 13 200-206

Benoit AM and Dailey RA (1991) Catheterization of the caudal vena cava via the lateral saphenous vein in the ewe, cow, and gilt: an alternative to the utero-ovarian and medial coccygeal vein catheters Journal of Animal Science 69 2971-2979

Bon GG, Kenemans P, Dekker JJ, Hompes PG, Verstraeten RA, van Kamp GJ and Schoemaker J (1999) Fluctuations in CA 125 and CA 153 serum concentrations during spontaneous ovulatory cycles Human Reproduction 14 566-570

Bowen JA, Bazer FW and Burghardt RC (1996) Spatial and temporal analysis of integrin and Muc-1 expression in porcine uterine epithelium and trophectoderm in vitro. Biology of Reproduction 55 1098-1106

Demmers KJ, Derecka K and Flint A (2001) Trophoblast interferon and pregnancy Reproduction 121 41-49

DeSouza MM, Surveyor GA, Price RE, Julian J, Kardon R, Zhoa X, Gendler SJ, Hilkens J and Carson DD (1999) Muc-1/episialin: a critical barrier to the female reproductive tract Journal of Reproductive Immunology $\mathbf{4 5}$ 127-158

Feeley KM and Wells $\mathbf{M}$ (2001) Precursor lesions of ovarian epithelial malignancy Histopathology 38 87-95

Fendrick JL, Konishi I, Geary SM, Parmley TH, Quirk JG and O'Brien TJ (1997) CA 125 phosphorylation is associated with its secretion from the WISH human amnion cell line Tumor Biology 18 278-289

Gray CA, Bartol FF, Tarleton BJ, Wiley AA, Johnson GA, Bazer FW and Spencer TE (2001) Developmental biology of uterine glands Biology of Reproduction 65 1311-1323

Henricks DM and Harris RB (1978) Cytoplasmic estrogen receptors and estrogen concentrations in bovine uterine endometrium Endocrinology 103 176-185 
Hoffman LH, Olson GE, Carson DD and Chilton BS (1998) Progesterone and implanting blastocysts regulate Muc 1 expression in rabbit uterine epithelium Endocrinology 139 266-271

Hudson MJ, Stamp GW, Chaudhary KS, Hewitt R, Stubbs AP, Abel PD and Lalani E-N (2001) Human MUC1 mucin: a potent glandular morphogen Journal of Pathology 194 373-383

Johnson GA, Bazer FW, Jaeger LA, Ka H, Garlow JE, Pfarrer C, Spencer TE and Burghardt RC (2001) Muc-1, integrin, and osteopontin expression during the implantation cascade in sheep Biology of Reproduction $\mathbf{6 5}$ 820-828

Marth C, Zeimet AG, Widschwendter M and Daxenbichler G (1998) Regulation of CA 125 expression in cultured human carcinoma cells International Journal of Biological Markers 13 207-209

Mayer MM (1984) Complement. Historical perspectives and some current issues Complement $12-26$

Meyer T and Rustin GJ (2000) Role of tumour markers in monitoring epithelial ovarian cancer British Journal of Cancer 82 1535-1538

Morgan BP and Holmes CH (2000) Protecting the placenta Current Biology 10 R381-R383

Murdoch WJ and McDonnel AC (2002) Roles of the ovarian surface epithelium in ovulation and carcinogenesis Reproduction 123 743-750

Nouwen EJ, Dauwe S and De Broe ME (1990) Occurrence of the mucinous differentiation antigen CA125 in genital tract and conductive airway epithelia of diverse mammalian species (rabbit, dog, monkey) Differentiation 45 192-198

O'Brien TJ, Tanimoto H, Konishi I and Gee M (1998) More than 15 years of CA 125: what is known about the antigen, its structure and its function International Journal of Biological Markers 13 188-195

O'Brien TJ, Beard JB, Underwood LJ, Dennis RA, Santin AD and York L (2001) The CA 125 gene: an extracellular superstructure dominated by repeat sequences Tumor Biology 22 348-366

Paoletti AM, Serra GG, Mais V, Ajossa S, Guerriero S, Orru M and Melis GB (1995) Involvement of ovarian factors magnified by pharmacological induction of multiple follicular development (MFD) in the increase in
Ca 125 occurring during the luteal phase and first 12 weeks of induced pregnancies Journal of Assisted Reproduction and Genetics 12 263-268

Prejean C and Colamonici OR (2000) Role of the cytoplasmic domains of the type I interferon receptor subunits in signaling Seminars in Cancer Biology 10 83-92

Roberts RM, Cross JC and Leaman DW (1992) Interferons as hormones of pregnancy Endocrine Reviews 13 432-452

Robinson RS, Mann GE, Lamming GE and Wathes DC (2001) Expression of oxytocin, oestrogen and progesterone receptors in uterine biopsy samples throughout the oestrous cycle and early pregnancy in cows Reproduction 122 965-979

Staggs KL, Austin KJ, Johnson GA, Teixeira MG, Talbott CT, Dooley VA and Hansen TR (1998) Complex induction of bovine uterine proteins by interferon-tau Biology of Reproduction 59 293-297

Surveyor GA, Gendler SJ, Pemberton L, Das SK, Chakraborty I, Julian J, Pimental RA, Wegner CC, Dey SK and Carson DD (1995) Expression and steroid hormonal control of muc-1 in the mouse uterus Endocrinology 136 3639-3647

Weems CW, Lee CN, Weems YS and Vincent DL (1988) Distribution of progesterone to the uterus and associated vasculature of cattle Endocrinologica Japonica 35 625-630

Yin BWT and Lloyd KO (2001) Molecular cloning of the CA125 ovarian cancer antigen Journal of Biological Chemistry 27627 371-27 375

Zeimet AG, Offner FA, Müller-Holzner E, Widschwendter M, Abendstein B, Fuith LC, Daxenbichler G and Marth C (1998) Peritoneum and tissues of the female reproductive tract as physiological sources of CA-125 Tumor Biology 19 275-282

Received 14 May 2003.

First decision 28 July 2003.

Revised manuscript received 30 July 2003.

Accepted 4 August 2003. 